\title{
Polyamide Dendrimers and Spermine Interact with DNA
}

\author{
Ali Elejmi ${ }^{1}$, Asma Abdalgader ${ }^{1}$, Wael Elhrari ${ }^{2}$, Inass A Sadawe ${ }^{3}$, Abdulathim A Alshoushan ${ }^{4}$, Nisreen H \\ Meiqal $^{3}$, Jamal Ali Elbakay ${ }^{3}$, Salah M Bensaber ${ }^{3}$, Anton Hermann ${ }^{5}$ and Abdul M Gbaj ${ }^{3 *}$ \\ ${ }^{1}$ Department of Chemistry, Faculty of Science, University of Tripoli, Libya \\ ${ }^{2}$ Polymer Research Center, Libya \\ ${ }^{3}$ Department of Medicinal Chemistry, University of Tripoli, Libya \\ ${ }^{4}$ Food and Drug Control Centre (LFDA), Libya \\ ${ }^{5}$ Department of Biosciences, University of Salzburg, Austria
}

*Corresponding author: Abdul M Gbaj, Associate Professor of Genetics and Biochemistry, Department of Medicinal Chemistry, Faculty of Pharmacy, University of Tripoli, Libya.

Received Date: November 28, 2019

Published Date: December 06, 2019

\begin{abstract}
Polyamines and polyamide dendrimers based on tetraethyl-1,1,3,3-propanetetracaroxylate positively charged organic cations under physiologic ionic- and $\mathrm{pH}$ conditions and therefore interact with negatively charged sites at double stranded Deoxyribo nucleic Acid(dsDNA). The interaction of these dendrimers with the DNA double helix has been studied with two generations $(\mathrm{G}): \mathrm{G}_{2}-\mathrm{NH}_{2}, \mathrm{G}_{4}-\mathrm{NH}_{2}$. The binding properties of the two generations were examined by ethidium bromide (EtBr) displacement using fluorescence spectroscopy. It has been shown that $\mathrm{G}_{2}-\mathrm{NH}_{2}$ and $\mathrm{G}_{4}-\mathrm{NH}_{2}$ dendrimers can interact with dsDNA through an intercalative binding mode as its displaced EtBr from the dsDNA-dye complex. The electrostatic interaction is the main mode of polyamine-nucleic acid interactions. In conclusion, the synthetic dendrimer polymers appear most interesting and highly promising candidates as DNA-interactive drugs that have antitumor activity.
\end{abstract}

Keywords: DNA-interactive agents; Dendrimers polymer, Chemotherapeutic intervention, Ethidium bromide

\section{Introduction}

DNA represents a major target for chemotherapeutic strategy in human cancers, particularly for those where elevated proliferation rates of some tumor cell types have resulted in sensitivity to drugs, which obstruct transcription and replication of their DNA [1]. Plenty of research projects are endeavored designing new molecules that are able to interact with the double stranded DNA (dsDNA) of tumor cells. Among DNA recognizing small molecules, intercalators represent an important group of potential anticancer drugs [2,3]. Ethidium bromide is a cationic dye and can interact with ds DNA by intercalation between the base pairs [4-7]. The fluorescent complex between ethidium bromide and DNA was reported previously [4-7]. A large increase in fluorescence is observed when ethidium bromide intercalates DNA making it a useful probe to measure drug-DNA interactions [8-10].There are two binding sites where ethidium bromide can bind to the DNA: a primary site, which has been interpreted as intercalation between base pairs, and a secondary site, which is considered to serve for electrostatic interactions, between the cationic ethidium bromide and the anionic phosphate groups located at the DNA surface [11,12].

The polyamines, spermine and spermidine and their diamine precursor putrescine are naturally occurring, polycationic alkylamines that are essential for the cell growth. The need of polyamines is often dysregulated in cancer and other hyperproliferative diseases, it therefore appears eligible making polyamine function and metabolism an important target for therapeutic intervention [13-15]. Many cationic polymers such as polylysine, polyethylenimine and fractured dendrimers can interact with DNA and form a complex. These polymers interact with DNA through electrostatic interaction forming a unit structure with toroidal morphology. The level of aggregation of the unit structures in solution depends on the features of the individual polymer [16]. Dendrimers are a class of polymers which distinguishes them 
from linear polymers by their remarkable chemical and physical properties, which can be controlled during their synthesis. They are normally synthesized from a central polyfunctional core, branching segment and a surface called periphery. The periphery segments are the most effective parts in the dendrimers, they control the solubility and bioactivity. The potential of using dendrimers as vessels or hosts for other molecules was strikingly demonstrated by many researchers [17-20]. Amine terminal groups adds positive charge to the surface of dendrimersthat can be used for electrostatic drug interactions. Polyamide dendrimer based on tetraethyl1,1,3,3-propanetetracaroxylate synthesized through repeating amide formation of 1,6-diaminohexane with adipoyl chloride, tris(hydroxymethyl) aminomethane was introduced as branching point. The main aim of our study was to explore the ability of polyamines and polyamidedendrimers polymers to displace the ethidium bromide binding dye from the genomic DNA giving the opportunity to create new effective substances for cancer therapy.

\section{Materials and Methods}

Table 1 summaries the chemical structures of the compounds used in the study. Spermine dihydrate was purchased from Sigma Aldrich, cat No. 85588. The $\mathrm{G}_{2}-\mathrm{NH}_{2}$ and $\mathrm{G}_{4}-\mathrm{NH}_{2}$ were obtained from Dr. Ali Elejmi's team (Chemistry Department, Tripoli University) (Table 1).

Table 1: Chemical structures of spermine, G2-NH2 and G4-NH2 molecules.

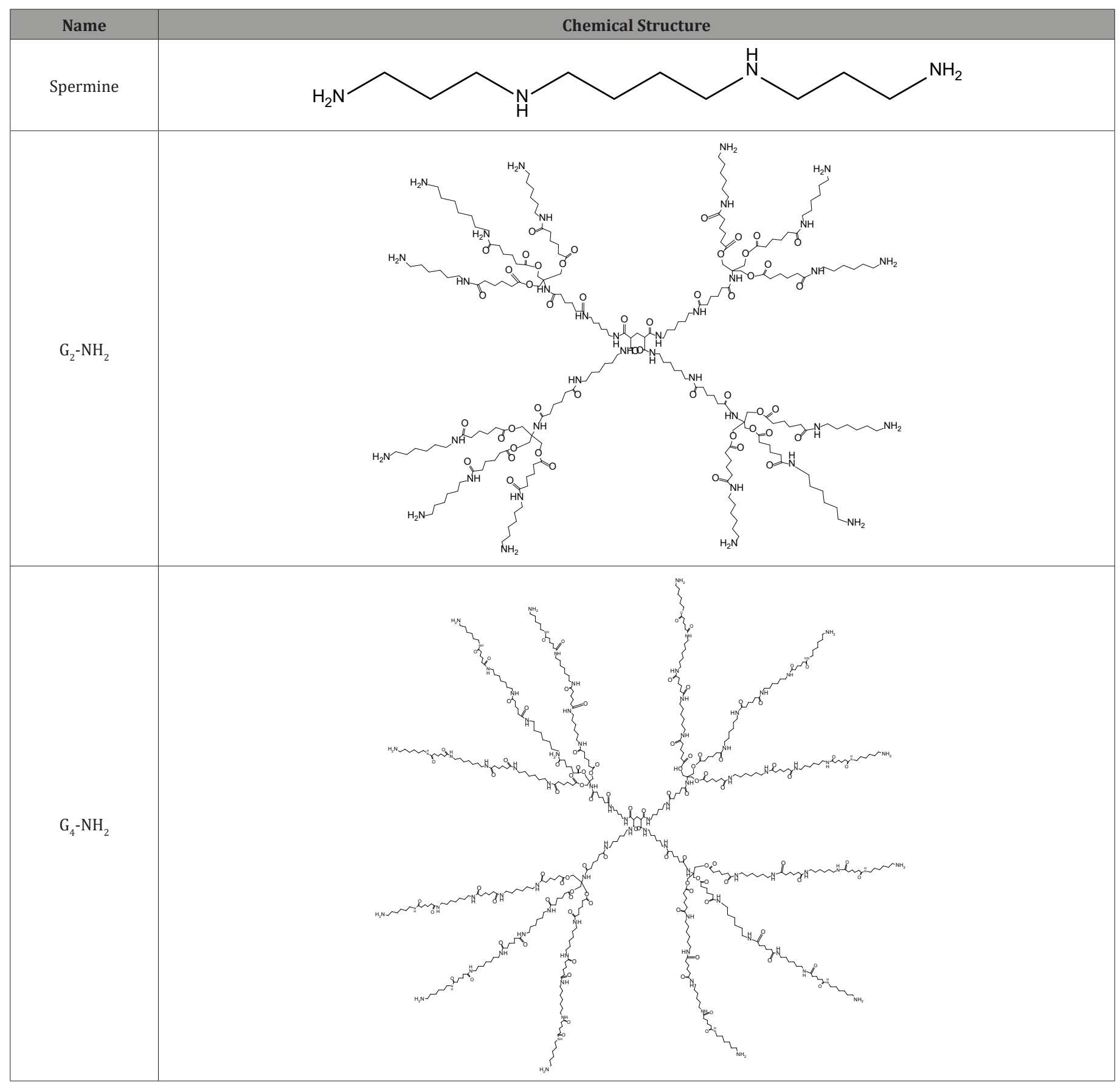

\section{DNA binding properties}

To study how competently the synthesized compounds, interact with genomic DNA (G-DNA), we investigated their DNA binding ability using fluorescence emission spectra. All experiments were conducted in Tris buffer $(0.01 \mathrm{M}$ Tris, $0.1 \mathrm{M} \mathrm{NaCl}$, at pH 7.4). Glassdistilled deionized water and analytical grade reagents were used 
throughout experiments. $\mathrm{pH}$ values of solutions were measured with a calibrated Jenway pH-meter model 3510 (Staffordshire, UK). All buffer solutions were filtered through Millipore filters (Millipore, UK) of $0.45 \mathrm{~mm}$ pore diameter.

\section{Absorbance spectra}

Absorbance spectra were measured on a Jenway UV-visible spectrophotometer, model 6505 (London, UK) using quartz cells of $1.00 \mathrm{~cm}$ path length. The UV-Vis absorbance spectra were recorded in the 200-500 $\mathrm{nm}$ range and a spectral bandwidth of $3.0 \mathrm{~nm}$. For the final spectrum of each solution analyzed baseline subtraction of the buffer solution was performed. Genomic DNA was used in a concentration of $75 \mu \mathrm{g} / \mathrm{ml}$. DNA was extracted from peripheral lymphocytes of anticoagulated blood (EDTA) sampled by Proteinase $\mathrm{K}$ digestion and phenol/chloroform extraction [21]. The purity was determined by measuring the absorbance at $260 / 280 \mathrm{~nm}$ indicating that the sample was free from protein contamination [21]. The concentration was assayed spectrophotometrically using $6600 \mathrm{M}-1 \mathrm{~cm}-1$ as a molar extinction coefficient at $260 \mathrm{~nm}$.

\section{Fluorescence spectra and DNA-binding studies}

Fluorescence emission and excitation spectra were measured using a Jasco FP-6200 spectrofluorometer (Tokyo, Japan) using fluorescence 4-sided quartz cuvettes of $1.00 \mathrm{~cm}$ path length. The automatic shutter-on function was used to minimize photo bleaching of the sample. The selected excitation wavelength for ethidium bromide was $480 \mathrm{~nm}$. The emission spectrum was corrected for background fluorescence of the buffer. Ethidium bromide (EB) fluorescence displacement experiment were performed by sequential addition of aliquots of $1790 \mu \mathrm{l}$ Tris buffer, $10 \mu \mathrm{l} \mathrm{EB}$ (final concentration of $72 \mu \mathrm{M}$ ), $100 \mu \mathrm{l}$ G-DNA from stock solutions $(1.5 \mathrm{mg} / \mathrm{ml})$ and finally $10 \mu \mathrm{l}$ of compounds (spermine, $\mathrm{G}_{2}-\mathrm{NH}_{2}$ and $\mathrm{G}_{4}-\mathrm{NH}_{2}$ final concentration of $50 \mu \mathrm{M}$ ). Emission spectra were recorded for each system using excitation wavelengths of maximum fluorescence intensity determined for the systems at to be480 $\mathrm{nm}$ using a slit width of $5 \mathrm{~nm}$ to examine alterations in emission spectra resulting from the complex construction of both systems. After completion of the full systems, the system was allowed to equilibrate for 30 minutes at room temperature and emission spectra (500-730nm) were recorded to monitor changes in EB intensity.

\section{Result and Discussion}

\section{DNA binding properties}

Measurement of the capability of ligands to displace ethidium bromide from genomic DNA is established as a suitable measurement of DNA binding ability for both intercalative and nonintercalative drugs. The displacement of ethidium bromide from DNA provides an indirect method of measuring the binding affinity of drugs that lack a chromophore as in case of spermine, $\mathrm{G}_{2}-\mathrm{NH} 2$ and $\mathrm{G}_{4}-\mathrm{NH}_{2}$. To study how effective the three compounds interact with G-DNA, the DNA primary binding properties were explored by using fluorescence emission spectroscopy. Fluorescence emission experiments have been extensively used to study the spermine,
$\mathrm{G}_{2}-\mathrm{NH}_{2}$ and $\mathrm{G}_{4}-\mathrm{NH}_{2}$ compound-DNA interactions, in which the fluorescence emissions of ethidium-DNA complex was decreased significantly in the presence of these compounds, which is in good agreement with fluorescence results of other intercalators reported in the literature [22]. The results indicate that all three compounds can interact with G-DNA. It is well established in the literature that polyamines have multiple positive charges in vivo and in vitro due to protonation of the amine groups, they will interact with negatively charged polynucleic acids. It has been estimated that a large amount of polyamines available in cells are associated with DNA or RNA [23]. Polyamines have been shown to provoke DNA condensation and to stabilize compact forms of DNA [24]. Polyamines are also able to promote secondary structural transitions of DNA with the B-Z transition of alternating purine/ pyrimidine oligonucleotides in solution [25]. All these features effect the fluorescence of ethidium bromide when it is displaced from the DNA by polyamines or polymers.

\section{EB competition assay}

The structural properties of the complex formed between genomic DNA and ethidium bromide using Raman microscopy equipped with near-infrared laser excitation was studied by Tsuboi, [26]. The study showed that the phenanthridinium plane is tilted by $35 \pm 5^{\circ}$ from the plane perpendicular to the fiber (DNA helix) axis. The study also assumed coplanarity of the phenanthridiniumbyring and its immediate base neighbors at the intercalation site. Such bases would have a tilt angle closer to that of A-DNA $\left(20^{\circ}\right)$ compared to B-DNA $\left(6^{\circ}\right)$ and the average base tilt in stretches of DNA between intercalation sites remains that of B-DNA [26]. In our experiments the entrenched quenching assay based on the displacement of the intercalating dye, ethidium bromide (EB), from G-DNA was utilized to explore the interaction mode between the complexes and G-DNA. EB is an extremely helpful DNA probe, which exhibits a significant increase in fluorescence intensity when intercalating into the base pair of DNA. However, the increased fluorescence can be obviously quenched when a second complex can replace the bound EB or break the secondary structure of DNA $[27,28]$. It has been shown that the groove DNA binders possibly cause the decrease in EB emission intensities [29,30]. The entire compounds do not fluoresce with an excitation at $612 \mathrm{~nm}$.

The EB competition assay results are shown in Figure 1. The fluorescence intensity of DNA-bounded EB at $612 \mathrm{~nm}$ decreased substantially in the presence of spermine, $\mathrm{G}_{2}-\mathrm{NH}_{2}$ or $\mathrm{G} 4-\mathrm{NH}_{2}$. This decrease in fluorescence intensity may be due to the quenching of some EB molecules that were released from DNA into the solution after being substituted by spermine, $\mathrm{G}_{2}-\mathrm{NH} 2$ and $\mathrm{G} 4-\mathrm{NH}_{2}$ compounds. A similar phenomenon of fluorescence quenching caused by DNA - compound interactions has been reported previously [29,30] (Figure 1).

In addition, it has been reported that polyamine binding to DNA in the presence of ethidium bromide forming a polyamineDNA complex was not completely responsible for the release of ethidium bromide. Polyamines in high concentration induces DNA 
bending leading to conformational changes within the double helix that helps the release of bound ethidium bromide [31,32]. Spermine, $\mathrm{G}_{2}-\mathrm{NH}_{2}$ and $\mathrm{G}_{4}-\mathrm{NH}_{2}$ have polybasic character. The three compounds bind strongly to genomic DNA molecules and stabilize them by neutralizing negative charges of phosphate groups and by decreasing the repulsion between complementary strands. The fluorescence quenching activity obtained in this study could be related to DNA condensation which generally depends on the positive charge of polyamines and this is consistent with reports in the literature [33-35]. In spermine the distance between amino groups attached to carbon atoms is nearly the same as the distance between phosphate anions in the DNA backbone. This makes spermine an ideal molecule for creating a zwitterionic structure that often perk up target affinity to DNA. This may explain the pattern that $\mathrm{G}_{2}-\mathrm{NH}_{2}$ and $\mathrm{G}_{4}-\mathrm{NH}_{2}$ bind to DNA even they are big molecules.

The literature also confirms that polyamines and their polymers bind to the DNA. It is reported that both electrostatic and chemical interactions take place in polyamine-DNA binding using Raman spectroscopy [36,37]. In addition, modeling, x-ray diffraction, and solution studies have emphasized our understanding of interactions between polyamines and nucleic acids. Polyamines appear to ccupy specific sites, particularly the major and minor grooves, in different DNA conformations [38-40].

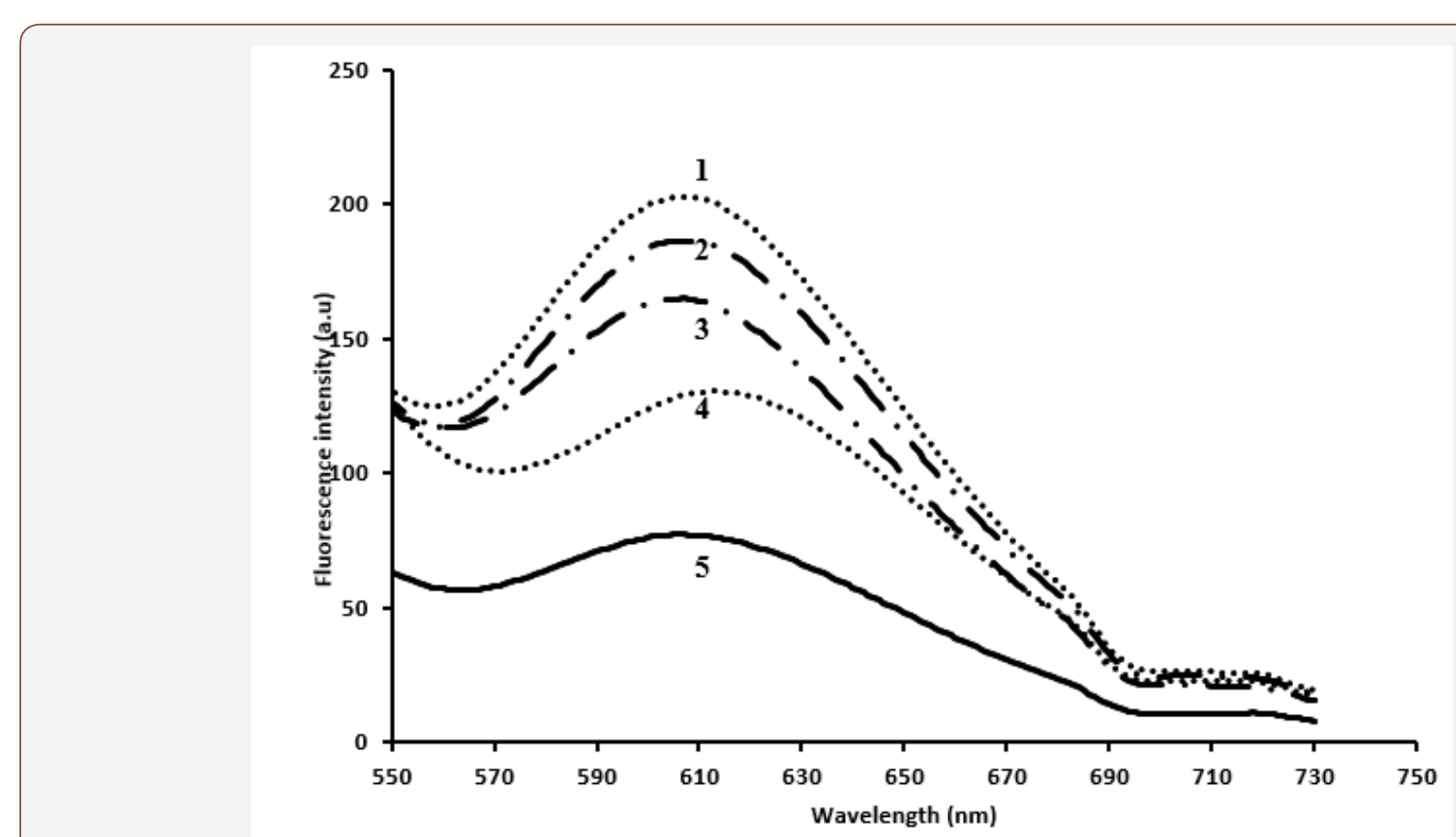

Figure 1: Fluorescence changes of ethidium bromide that contains (1) G-DNA-ethidium bromide complex, (2) G-DNA-ethidium bromide complex with $50 \mu \mathrm{m}$ spermine (3) G-DNA-ethidium bromide complex with $50 \mu \mathrm{m}$ G4-NH2(4) ethidium bromide alone and (5) G-DNA-ethidium bromide complex with $50 \mu \mathrm{m}$ G2-NH2. Experiments were conducted in solutions containing: Tris buffer $(0.01 \mathrm{M} \mathrm{Tris,}, 0.1 \mathrm{M} \mathrm{NaCl}$, at pH 7.4, $\lambda \mathrm{ex}$ $=480 \mathrm{~nm}$. Genomic DNA was used in a concentration of $75 \mu \mathrm{g} / \mathrm{ml}$ and ethidium bromide $72 \mu \mathrm{M}$.

As shown is Figure 1, compound $\mathrm{G}_{2}-\mathrm{NH}_{2}$ had the highest quenching efficacy suggesting that compound $\mathrm{G} 2-\mathrm{NH} 2$ attaches most tightly to G-DNA - even more than spermine and $\mathrm{G}_{4}-\mathrm{NH}_{2}$. The differences in the fluorescence quenching ability between $\mathrm{G}_{2}-\mathrm{NH}_{2}$ and $\mathrm{G}_{4}-\mathrm{NH}_{2}$ could be related to the fact that the conformational change of the double stranded DNA molecule induced by $\mathrm{G}_{2}-\mathrm{NH}_{2}$ is more pronounced than by $\mathrm{G}_{4}-\mathrm{NH}_{2}$. A reason may be that the chain branch lengths in $\mathrm{G}_{2}-\mathrm{NH}_{2}$ are shorter than the branches lengths in $\mathrm{G}_{4}-\mathrm{NH}_{2}$ dendrimers. ThusG $\mathrm{G}_{4}-\mathrm{NH}_{2}$ dendrimers are less flexible and bulky, as a result of the increase of hydrogen bonds as branches increase. This result is confirmed by other researchers [16]. Moreover, the results shed light on the periphery interaction of dendrimers with DNA rather than at interior segments.

\section{Conclusion}

In conclusion, the polyamine field, predominantly in relation to cancer and other hyperproliferative disorders, is at an exciting stage. The molecular mechanisms related to polyamine function are now becoming more obvious, creating an enhanced understanding of the differential requirements for polyamines in tumor cells versus normal cells. In our study the DNA binding of the spermine, $\mathrm{G}_{2}-\mathrm{NH}_{2}$ and $\mathrm{G}_{4}-\mathrm{NH}_{2}$ was investigated by fluorescence spectral techniques and revealed an intercalative interaction between them and G-DNA. Among the investigated three compounds G2-NH2 showed the highest quenching affinity. Furthermore, the study provides evidence that the bulkiness of the molecules play role in the interaction with DNA.

\section{Acknowledgement}

None.

\section{Conflict of Interest}

The authors declare that the research was conducted in the absence of any commercial or financial relationships that could be construed as a potential conflict of interest. 


\section{References}

1. Kumar R, Lown JW (2005) Design, synthesis and in vitro cytotoxic studies of novel bis-pyrrolo[2,1][1,4] benzodiazepine-pyrrole and imidazole polyamide conjugates. Eur J Med Chem 40(7): 641-654.

2. Godzieba M, Ciesielski S (2019) Natural DNA Intercalators as Promising Therapeutics for Cancer and Infectious Diseases. Curr Cancer Drug Targets.

3. Xu YH, Li W, Rao Y, Huang ZS, Yin S (2019) Pyridocarbazole alkaloids from Ochrosia borbonica: lipid-lowering agents inhibit the cell proliferation and adipogenesis of 3T3-L1 adipocyte via intercalating into supercoiled DNA. Chin J Nat Med 17(9): 663-671.

4. Houssier C, Hardy B, Fredericq E (1974) Interaction of ethidium bromide with DNA. Optical and electrooptical study. Biopolymers 13(6): 1141-1160.

5. Bontemps J, Fredericq E (1974) Comparative binding study of the interaction of quinacrine and ethidium bromide with DNA and nucleohistone. Biophys Chem 2(1): 1-22.

6. Williams RE, Seligy VL (1974) The interaction of ethidium bromide with synthetic polydeoxyribonucleic acids. Effect of base composition and sequence on the induced circular dichroism spectra. Can J Biochem 52(4): 281-287.

7. Ward DC, Reich E, Goldberg IH (1965) Base specificity in the interaction of polynucleotides with antibiotic drugs. Science 149(3689): 12591263.

8. Radisavljevic S, Cocic D, Jovanovic S, Smit B, Petkovic M, et al. (2019) Synthesis, characterization, DFT study, DNA/BSA-binding affinity, and cytotoxicity of some dinuclear and trinuclear gold(III) complexes. J Biol Inorg Chem 24(7): 1057-1076.

9. Lopez Lopez M, Lopez Cornejo P, Martin, Ostos FJ, Checa Rodriguez C, et al. (2018) Importance of hydrophobic interactions in the single-chained cationic surfactant-DNA complexation. J Colloid Interface Sci 521: 197205.

10. Yalcin E, Duyar H, Ihmels H, Seferoglu Z (2018) Spectroscopic studies on the interactions of 5-ethyl-6-phenyl-3,8-bis((3-aminoalkyl) propanamido)phenanthridin-5-ium derivatives with G-quadruplex DNA. Spectrochim Acta A Mol Biomol Spectrosc 196: 432-438.

11. Reinert KE (1973) DNA stiffening and elongation caused by the binding of ethidium bromide. Biochim Biophys Acta 319(2): 135-139.

12. Rucheton M, Jeanteur P (1973) Studies on amikhellin. I. Intercalative binding to double-stranded DNA. Biochimie 55(11): 1415-1420.

13. Lorenz B, Francis F, Gempel K, Boddrich A, Josten M, et al. (1998) Spermine deficiency in Gy mice caused by deletion of the spermine synthase gene. Hum Mol Genet 7(3): 541-547.

14. Han LP, Yuan LB, Shentu YP, Shao JD (2013) Spermine reduced no-reflow size induced by ischemia-reperfusion through regulating autophagy. Int J Cardiol 168(3): 3145-3147.

15. Keniry MA, Owen EA (2013) Insight into the molecular recognition of spermine by DNA quadruplexes from an NMR study of the association of spermine with the thrombin-binding aptamer. J Mol Recognit 26(7): 308-317.

16. Tang MX, Szoka FC (1997) The influence of polymer structure on the interactions of cationic polymers with DNA and morphology of the resulting complexes. Gene Ther 4(8): 823-832.

17. Menjoge AR, Kannan RM, Tomalia DA (2010) Dendrimer-based drug and imaging conjugates: design considerations for nanomedical applications. Drug Discov Today 15(5,6): 171-185.

18. Mishra V, Yadav N, Saraogi GK, Tambuwala MM, Giri N (2019) Dendrimer Based Nanoarchitectures in Diabetes Management: An Overview. Curr Pharm Des 25(23): 2569-2583.

19. Sharma P, Mehta M, Dhanjal DS, Kaur S, Gupta G, et al. (2019) Emerging trends in the novel drug delivery approaches for the treatment of lung cancer. Chem Biol Interact 309: 108720.
20. Hooshyar SP, Mehrabian RZ, Panahi HA, Jouybari MH, Jalilian H (2019) Synthesis and characterization of magnetized-PEGylated dendrimer anchored to thermosensitive polymer for letrozole drug delivery. Colloids Surf B Biointerfaces 176: 404-411.

21. Johns MB, Paulus Thomas JE (1989) Purification of human genomic DNA from whole blood using sodium perchlorate in place of phenol. Anal Biochem 180(2): 276-278.

22. Kuruvilla E, Joseph J, Ramaiah D (2005) Novel bifunctional acridineacridinium conjugates: synthesis and study of their chromophoreselective electron-transfer and DNA-binding properties. J Phys Chem B 109(46): 21997-22002.

23. Watanabe S, Kusama Eguchi K, Kobayashi H, Igarashi K (1991) Estimation of polyamine binding to macromolecules and ATP in bovine lymphocytes and rat liver. J Biol Chem 266(31): 20803-20809.

24. Bloomfield VA (1991) Condensation of DNA by multivalent cations: considerations on mechanism. Biopolymers 31(13): 1471-1481.

25. Wemmer DE, Srivenugopal KS, Reid BR, Morris DR (1985) Nuclear magnetic resonance studies of polyamine binding to a defined DNA sequence. J Mol Biol 185(2): 457-459.

26. Tsuboi M, Benevides JM, Thomas GJ (2007) The Complex of Ethidium Bromide with Genomic DNA: Structure Analysis by Polarized Raman Spectroscopy. Biophys J 92(3): 928-934.

27. Zhang QQ Zhang F, Wang WG, Wang XL (2006) Synthesis, crystal structure and DNA binding studies of a binuclear copper(II) complex with phenanthroline. J Inorg Biochem 100(8): 1344-1352.

28. Jiang M, Li YT, Wu ZY, Liu ZQ Yan CW (2009) Synthesis, crystal structure, cytotoxic activities and DNA-binding properties of new binuclear copper(II) complexes bridged by N,N'-bis(N-hydroxyethylaminoethyl) oxamide. J Inorg Biochem 103(5): 833-844.

29. Prunkl C, Pichlmaier M, Winter R, Kharlanov V, Rettig W, et al. (2010) Optical, redox, and DNA-binding properties of phenanthridinium chromophores: elucidating the role of the phenyl substituent for fluorescence enhancement of ethidium in the presence of DNA. Chemistry 16(11): 3392-3402.

30. Garbett NC, Hammond NB, Graves DE (2004) Influence of the amino substituents in the interaction of ethidium bromide with DNA. Biophys J 87(6): 3974-3981.

31. Delcros JG, Sturkenboom MC, Basu HS, Shafer RH, Feuerstein BG, et al. (1993) Differential effects of spermine and its analogues on the structures of polynucleotides complexed with ethidium bromide. Biochem J 291(Pt 1): 269-274.

32. Thomas TJ, Kulkarni GD, Greenfield NJ, Shirahata A, Thomas T (1996) Structural specificity effects of trivalent polyamine analogues on the stabilization and conformational plasticity of triplex DNA. Biochem J 319(Pt 2): 591-599.

33. Lee CY, Su GC, Huang WY, Ko MY, Yeh HY, et al. (2019) Promotion of homology-directed DNA repair by polyamines. Nat Commun 10(1): 65.

34. Lindemose S, Nielsen PE, NE Mollegaard (2005) Polyamines preferentially interact with bent adenine tracts in double-stranded DNA. Nucleic Acids Res 33(6): 1790-1803.

35. Nishio T, Yoshikawa Y, Shew CY, Umezawa N, Higuchi T, et al. (2019) Specific effects of antitumor active norspermidine on the structure and function of DNA. Sci Rep 9.

36. Chen Y, Dai J, Zhou X, Liu Y, Zhang W, et al. (2014) Raman Spectroscopy Analysis of the Biochemical Characteristics of Molecules Associated with the Malignant Transformation of Gastric Mucosa. PLoS One 9(4): e93906.

37. Deng H, Bloomfield VA, Benevides JM, Thomas GJ (2000) Structural basis of polyamine-DNA recognition: spermidine and spermine interactions with genomic B-DNAs of different GC content probed by Raman spectroscopy. Nucleic Acids Res 28(17): 3379-3385.

38. Lin J, Chen H, Droge P, Yan J (2012) Physical Organization of DNA by Multiple Non-Specific DNA-Binding Modes of Integration Host Factor (IHF). PLoS One 7(11): e49885. 
39. Korolev N, Lyubartsev AP, Laaksonen A, Nordenskiold L (2003) A molecular dynamics simulation study of oriented DNA with polyamine and sodium counterions: diffusion and averaged binding of water and cations. Nucleic Acids Res 31(20): 5971-5981.
40. Deng H, Bloomfield VA, Benevides JM, Thomas GJ (2000) Structural basis of polyamine-DNA recognition: spermidine and spermine interactions with genomic B-DNAs of different GC content probed by Raman spectroscopy. Nucleic Acids Res 28(17): 3379-3385. 